\section{CLINICAL LECTURE}

\section{SOME OF THE SYMPTOMS OF GRAVES'S DISEASE.}

BY DAVID DRUMMOND, M.A., M.D.,

Physician and Pathologist to the Newcastle-on-Tyne Infirmary.

Gentlemen, - I wish to-day to draw your attention to a few of the features of exophthalmic goître, and especially to some that have, I believe, received too little notice. I shall introduce three patients for you to examine, and shall refer briefly to the histories of some others, whose cases most of you will recollect.

The first case is that of the young woman, a general servant, who was admitted into No. 12 Ward a few weeks ago. She is complaining of palpitation, shortness of breath, a swelling in the neck, and proptosis or exophthalmos. Her father and mother are living and well ; one sister had an attack of hemiplegia at the age of 2 years, and has since been subject to epileptic fits. Our patient has always had a comfortable home, and has been free from mental anxiety or want. In her work she has been much exposed to cold, and has often had wet feet, but has never suffered from rheumatism. In January, 1886, twelve months ago, she was struck by the prominence of her eyes, and about the same time she became affected with shortness of breath on exertion. She grew steadily worse until March, when some improvement was apparent. In April she took typhoid fever, from which she made a very tardy recovery, and her previous symptoms, taking advantage of her weakness, returned in a more exaggerated way, though it was not until October, 1886, that the palpitation forced itself upon her attention; so that, as far as her information is reliable, the order in which the cardinal symptoms of the disease made their appearance was: enlarged thyroid, protrusion of the eyeballs, and palpitation, which, it is important to recollect, is not the most common sequence, for palpitation usually ushers in the symptoms, and this is followed by enlargement of the neck. However, I suspect that the dyspnœa, which she described as one of the earliest symptoms, was cardiac, as it only took place on exertion. Throbbing of the carotids was next noticed, and later the swollen thyroid was seen to have acquired a pulse. The catamenia have been fairly regular, but the discharge scanty, and she asserts that the thyroid distinctly enlarges during the periods.

As you may observe, the patient is somewhat anæmic. She is spare, but by no means emaciated. The eyes are prominent, and from time to time a ring of white sclorotic can be seen surrounding the cornea, giving the face a peculiar startled and staring appearance. But perhaps the most noticeable feature about the case is the dark pigmented areas around the eyes, the muddy duskiness of the face generally, the dark areola about the nipples, the brown axillæ, and the diacoloration of the skin of the upper and inner aspects of the thighs. The thyroid is enlarged, and feels soft and elastic, whilst a distinct bruit can be heard over it; and, further, it is affected by an expansile pulsation. A soft bruit can also be detected by the stethoscope placed over the eyeball, though none can be heard in the neighbourhood of the orbit. The beart is excited, the average number of pulsations per minute being about 110. The visible area of pulsation is increased, though the apex-beat is very slightly depressed. A soft blowing murmur, neplacing the first sound, is audible over the base of the heart, and is distinctly conducted up into the carotids. There is no murmur at the apex. The urine is freo from albumen and sugar ; it varies very much in quantity; for example, on one day 34 ounces were passed, whilst 70 were voided on the following, and 60 on the day after. In addition to the palpitation and other symptoms named, she has complained much of certain sub. jective sensations, such as tinnitus aurium, a throbbing in the head, vertigo, and a craving for food even after a full meal-an unusual symptom-anorexia being a common feature of Graves's disease. Then she tells us that she is now excessively nervous and easily frightened, whereas prior to the commencement of the illness she was in possession of marked self-control. You will observe that Graefe's sign is absent, or, in other words, when the eyes are depressed, the lids cover accurately the sclerotic margins of the cornex.

Now let us turn to the case of the other female patient before us.

$$
\text { [1376] }
$$

She is 47 years of age, married, and has a family. About eighteen months ago, when pregnant, she had a fall, which gave her a great shock and tright; this she regards as the chief cause ot her complaint. Very shortly after, palpitation became troublesome, and then the swelling of the thyroid was observed, and, lastly, proptosis appeared. You will observe that the skin of the face is bronzed, especially around the prominent eyes ; the anterior folds of the axillæ are considerably discoloured, as also are the areolæ of the mammie and the internal surfaces of the thighs. She is uncertain when the skin began to darken, but is of the impression that she first noticed the change about the time the palpitation commenced. You can compare her with her sister, who happens to accompany her, and who tells me that the patient's skin is much darker than it nsed to be. In her case, the symptom to which Graefe called attention is well marked. As she alters the plane of her vision, the lids, either upper or lower, as the case may be, hang fire, as it were, and reveal the sclerotic outside the cornea. The pulse averages 110. She complains much of palpitation, and the excited heart shows an increased area of pulsation. The thyroid is large, and pulsates; the eyes are prominent. Though very much improved, you will notice that she is still extremely nervous, and can with difficulty reply to one's questions.

Our next patient present is a man, aged 36 , an overseer in connection with the traffic department of a colliery. He is very intelligent, and has taken an unusual interest in the progress of his case. Two years ago, when in good health, he jumped from a locomotive, and "gave his whole system a shake." This, he imagines, was in some measure responsible for his symptoms, as the bronzing of the skin and palpitation came on soon after, the former distinctly preceding the latter. At first the pigmentation was on the face alone, but it extended rapidly from the cheeks to the neck, and soon after the wrists became affected. From being a calm self-possessed person he grew exceedingly nerrous and fidgety, and freq'ent attacks of violent palpitation distressed him sorely. He now began to complain of debility, and soon made the discovery that he was a completely altered man. The swelling of the thyroid appeared to come on suddenly, for when dressing one morning, some months later than the first appearance of the bronzing, he found that he could not button his collar, and now he observed for the first time a localised swelling in the front of the neck. After this the palpitation became more constant, and soon the protrusion of the eyeballs was detected. When I examined him first I was very much struck with the discoloration of the skin, and though it has certainly faded since then, you can still see the deep brown patches. You will observe the dark areas surrounding the eyes; the mahogany-coloured pigmentation of the cheeks, the well-marked staining all round the neck, which is bordered with areas of skin of apparently natural colour. Again, on the front of the thorax and on the dorsum of the forearms and wrists we find a similar staining. On the wrists, however, the appearances are strongly suggestive of leucoderma, as patches of white skin are surrounded by liver-coloured pigmentation.

The accompanying illustration, taken from a photograph, shows very well the pigmentation on the face and neck, though it scarcely brings out sufficiently the prominence of the eyeballs and the enlargement of the thyroid. The heart, thyroid, and eyes, are all strikingly typical, and Graefe's phenomenon is well shown. In addition to the signs named we cannot fail to be struck with the patient's nervousness-his hands are constantly trembling, and his speech is much interfered with; his forehead is bathed in perspiration, and it is with difficulty that he can stand without leaning against the wall.

I must now remind you of the case of a patient who was admitted into the wards some little time ago for sub acute anterior poliomyelitis and exophthalmic goitre, and to the former of which diseases she succumbed. She was a mantle-maker, aged 50. For many years she was troubled with palpitation, dysmenorrhœa, and general debility. She ceased to menstruate at the age of 48 . Six months before her admission to hospital indigestion and vomiting were added to her other troubles, and she became so prostrate that she was obliged to remain in bed for some weeks. Abcut this time a swelling in the region of the thyroid was noticed, and soon afterwards the paraplegia developed. 'T'wo or three months later the proptosis was observed.

When admitted, she presented the picture of a nervous, debilitated woman at the climacteric period. Her lower extremities were paralysed and much emaciated, and altogether she was a well-marked example of chronic, or sub-acute, atrophic spinal paralysis of Duchenne, a diagnosis that was verified by subsequent microscopic examination of the cord. The exophthalmos was pronounced; Graefe's symptom was marked; the pupils were somewhat dilated, and responded to 
light. The thyroid was enlarged, but without distinct pulse or thrill, and the bruit audible in it was apparently conducted from the carotids. The heart-apex was in its normal position. A loud systolic murmur could be heard at the base between the second costal cartilages, but loudest in the pulmonary area. There was no apex murmur. The average pulse was 104 , and the usual palpitation was present. The skin of the face was of a sallow, muddy colour, with well-marked pigmentation around the eyes. The areola of the nipples was very dark; the urine was normal. A few weeks after admission the paralytic lesion became active, and, rapidly ascending the cord, caused death, with implication of the diaphragm.

At the post-mortem examination, all present were struck with the thickness of the layer of fat that covered the abdomen and chest, though the body was by no means that of an obese, or even stout, person. It was an inch and a half thick over the abdomen, and half an inch over the thorax; and wherever fat is usually deposited in the body, there was a laxge accumulation; for example, the omentum, mesentery, pericardium, and heart were literally laden. The thyroid, with a small portion of the trachea, weighed six ounces; the tissue was firm, of a pink colour, and, on section, presented in many places a peculiar colloid appearance. The eyes were by no means so prominent as they had been before death; the orbits were very full of fat;

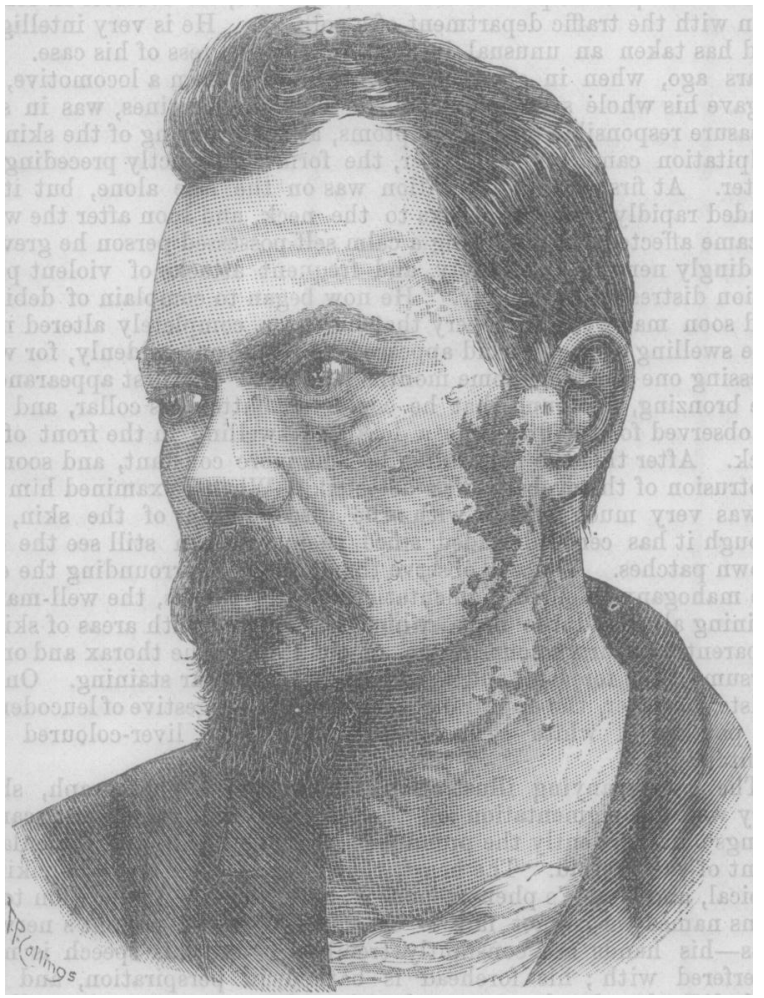

the heart weighed $8 \frac{1}{2}$ ounces ; the left ventricle was normal ; the right was dilated, and full of soft dark clot, which conveyed to the fingers a strange greasy feel, and, when examined close to the light, was seen to have fatty matter on the surface. There was no valvular impairment. The lungs were œdematous; the liver was small but the substance was normal in appearance ; two large gall-stones were found in the bladder, which also contained a quantity of mucus and cholesterin. With the exception of a general softness of consistency and some atheroma of the basal vessels, the brain was normal. The inferior cervical ganglia of the sympathetic were removed for microscopical examination, but to the naked eye they seemed normal. The spinal cord was reserved for examination, and, as I have already stated, showed distinct changes in anterior cornual groups of cells in the lumbar region. The upper dorsal and cervical positions were exceedingly soft ; indeed, in the middle and upper dorsal regions, the spinal marrow was reduced to a creamy substance, and quite defied all attempts at hardening. I should mention that distinct bronzing of the skin of the face, axillæ, nipple, and upper part of thighs was remarked at the post-mortem examination.
Most of you are already in possession of the facts of the case of Gertrude B., who quite recently died in Durham Ward. She was aged 28 , married, and was admitted complaining of palpitation, swelling of the neck, and prominence of the eyeballs. Her grandfather died of apoplexy, but with this exception the family history was devoid of interest. For upwards of five years before admission she suffered from palpitation and nervousness. The swelling of the thyroid was detected very early in the case, and brown discoloration of the face came on at the same time, namely, about five years ago. Three years subsequently she was immersed in the sea for fitteen minutes, owing to the upsetting of a boat, and nearly drowned. After this the palpitation and other nervous symptoms became very troublesome. Six months before she came under observation she married. She now experienced great domestic trouble, was badly used by her husband, who gave her gonorrhœa, and a little later she had a miscarriage. Her symptoms rapidly became aggravated, and she noticed that the skin of the axillæ, thighs, nipples, etc. was much darker than formerly. The exophthalmos also appeared about this time, and the friends were distressed at the change in her temperament, for she had become very irritable. When she was admitted into the infirmary, you will remember, we were much struck with her condition. The gcistre was pronounced, and the eyeballs stood out prominently, whilst the skin of the face (particularly the lids), neck, axillæ, nipples, flexor aspect of elbows, lower part of abdomen, and upper part of the thighs was considerably bronzed. Graefe's sign was not well marked. The swelling of the thyroid was symmetrical and pulsatile, and over it a loud, humming sound, intensified with each systole, was audible. The carotids pulsated violently. The apex-beat of the heart was normal in position, though there was a decidedly increased area of visible pulsation. A loud, aortic systolic bruit was heard, and, at times, the second sound at the base was reduplicated. The pulse ran, as a rule, from 112 to 115 in the minute. The tongue was protruded tremulously, and a nervous tremor of the hand was apparent on exertion. The urine contained sugar. She had little appetite, and frequently was troubled with nausea and vomiting. She was inclined to be morose and irritable, and disliked exceedingly any reference to her condition, so much so that it was with difficulty that her history was taken. Two or three weeks after her admission the nurse complained that the patient was excessively irritable and disagreeable with the other patients, that she refused to do what she was asked, and resented the slightest interference. Two days later she complained of dryness of the throat and great thirst, and the tongue was observed to be very red. She was kept in bed, and the next day delirium set in; she talked constantly, and at times grew very excited. The pulse now went up to 160 , and the temperature, which had been normal, rose to $101^{\circ}$. The excitement on the day following was very great, and her mind was filled with delusions; for example, the bed, she thought, was saturated with chloroform, and an attempt was being made to destroy her life in this way; or the students were taking liberties with her, and the nurse sold the patients for immoral purposes, etc. The pupils were widely dilated and did not respond to light. Next day it was impossible to keep her in bed, and she walked about the ward creating a great disturbance. She was now sleepless, and refused food; pulse 180 ; tongue dry and covered with sordes. Two days later, the excitement continuing, she became cyanosed, was still constantly talking, though in a less coherent and more feeble way; pulse 200 ; temperature $97^{\circ}$; death occurred siz days after the commencement of the mental excitement.

At the post-mortem examination, the body seemed to be somewhat emaciated, though, as in the other post-mortem examination referred to, a thick layer of fat lined the abdomen and chest. There was brown discoloration of the face, neck, axillæ, abdomen, and thighs. The thyroid was enlarged, and weighed seven and a half ounces, and measured four inches by four and a half. It was firm, and, on section, resembled remarkably the structure of the pancreas. The heart weighed twelve and a half ounces; the left ventricle was slightly hypertrophied, but not dilated; the right was dilated. The tricuspid orifice admitted four fingers. The mitral curtains were just a little thickened towards their free margins. The brain-substance was soft and œdematous. The vessels of the pia were injected. No arterial atheroma. The grey matter, superficial and basal, was of a dark purple colour from engorgement. The orbits contained a large quantity of fat, but no tortuous vessels or œdema could be seen ; the optic nerve (right) was decidedly elongated, and measured one inch and a half from the optic foramen to the globe ; the muscles of the eyeball were soft, friable, and evidently fatty. Not the slightest trace of Müller's musculus orbitalis was found. The sympathetic ganglia of the neck were removed for examination, and it was observed that the inferior ganglion on the right side was slightly matted with the surrounding parts. The medulla was also reserved for microscopical investigation; 
but I regret to say that I neglected to examine the cervical region of the cord.

I shall only trouble you with one more case, the features of which I may state very briefly :

A lady, aged 42, wnom I recently saw with Dr. Peart, of North Shields, had goître of five years' standing, and severe palpitation, dating from about the same period. About twelve months ago, the eyes became prominent, and a little later the face was observed to be pigmented. She received a fright, when staying at a hotel in a Yorkshire watering-place, a few months before I saw her, through a gentleman committing suicide in the bed-room adjoining hers, and since then she had been much worse. Soon after this her husband discovered that she was morose and gloomy, and that, without any reason, she neglected to notice him on his return from business. Then she began to refuse food, and took a dislike to all around her. Her irritability increased, and she became excessively suspicious; though weak from want of food, she could not be prevailed upon to remain in bed. When I saw her, she was morose and ignored one's questions ; was complaining of thirst and dryness of the mouth ; the tongue and throat were red ; the urine was saccharine ; the face was pigmented, and the anterior folds of the axillæ and the areolæ of the nipples were dark ; and the heart, thyroid, and eyes strongly suggested Graves's disease. In a day or two the depression gave place to excitement, and delirium set in. The heart went up to 150 in the minute, and seemed, as Dr. Peart remarked, "to run 3way." Then she became extremely restless, and rapidly sank. No post-mortem examination was made.

We have now before us six cases of exophthalmic goïtre; but, inasmuch as I recently reviewed the whole subject in some clinical remarks to the class, I shall confine myself to two points illustrated by these cases, and then I propose to call your attention to the pathology of the disease.

You must have been struck with the prominence I have given to the pigmentation of the skin. We have seen that in all the cases there was bronzing, more or less pronounced, and that in one this was associated with leucoderma or vitiligo. In some the appearances were practically those of Addison's disease, only in none were the minute, deeply-coluured patches of pigmentation on the arms, and the staining of the mucous membrane of the mouth, so characteristic of morbus Addisonii, made out. I may add that I have not yet met with this special distribution of pigment in Graves's disease, though I have at present a female out-patient, whom I wished to show you to-day, whose symptoms are highly suggestive. In her case there are all the features of Addison's disease ; great prostration, without material emaciation, vomiting and diarrhcea, pigmentation (arm, mouth, and general), and yet there is palpitation, with a slight tendency to proptosis, and a certain degree of enlargement of the thyroid.

The favourite situation for pigment in Graves's disease would appear to be around the prominent eyeballs, on the face generally, neck, axillæ, areola of nipples, abdomen, and upper and inner aspects of the thighs. The skin is smooth, and at times the patch is defined, or it may fade imperceptibly into the normally coloured skin. Wherever pigment occurs normally, there it is found increased, and the colour would appear to vary from a dirty, pale liver colour to a deep brown. The patches in our male patient are very dark indeed, and it is interesting to note that as the general condition has improved under treatment, so the patches of discoloration have become paler and smaller. In his case, especially on the wrists, we notice smooth, white patches of skin that are surrounded by areas of pigmentation.

To the occurrence of leucoderma in Graves's disease attention has been called by Trousseau, and later by Reynaud in 1875, and from time to time cases have been published in which leucoderma was a noticesble feature; but from what I have seen of late years of the disorder, I am convinced that sufficient stress has not been laid apon the changes of the skin, and that whereas true leucoderma is comparatively rare in exophthalmic goître, pigmentation allied to Addison's is one of the most constant signs of the disease, and is at least as deserving as Graefe's symptom to be included with so-called cardinal signs. The question arises, Is this pigmentation simply symptomatic of a general disorder, and akin to the discoloration so frequently noticed in cases of cancer, tuberculosis, malaria, in which it is probably in great measure the result of anæmia and irritation from central organs? Or is it to be ascribed directly to the nervechanges supposed to underlie Graves's disease, just as in the case of Addison's bronzing ? This is, of course, a difficult question to answer, and raises some very important points in the pathology of pigment deposit. On the whole, I am disposed to think that in these cases there is a peculiar disposition to the cutaneous deposit of pigment arising out of special and general causes, amongst which may be men- tioned perverted nerve-function, misapplied action of the thyroid (to which we vaguely ascribe hæmopoietic functions), great tendency to dilatation of the capillaries of the skin (witness Troussean's cerebral tache or macula), and anæmia.

All experienced in cases of exophthalmic goitre are familiar with the peculiar nervous and excilable temperament so often exhibited by the pationts, but comparatively few, judging from the paracity of records, sppesr to have witnessed the more pronounced symptoms of mental disturbance that developed towards the termination of the cases to which I have referred. I am anxious to impress upon you the general features of such disturbance, for it would appear that the occurrence of maniacal symptoms may generally be regarded as an exceedingly unfavourable prognostic indication. In the forty-first volume of Guy's Hospital Reports (1882), Dr. Savage describes three cases of Graves's disease in which there was depression followed by violent mania-mania of the destructive and incoherent kind; and he gives it as his experience that the disease (exophthalmic goitre) is more common among the insane than the sane. Again, he states that with the marked symptoms of Graves's disease (where insanity has been present), he has generally met with melancholy of the suspicious type, followed by mania of a very violent kind, and with a tendeney to emaciation and death. In this author's work on insanity, published in 1884, we have practically a repetition of these opinions with the additional statement that he has met with several cases of acute mental disorder with symptoms of exophthalmic goître which have completely recovered, with the loss of both the mental and bodily symptoms. He further reminds us that cases of general paralysis of the insane occur from time to time with one or all of the features of Graves's disease. Quite recently Dr. Collins, of Nottingham, published elinical notes of a case of this disease complicated with melancholia and occasional outbursts of maniacal excitement; this patient recovered.

I have not observed any reference to the condition of the urine in any of these cases, but you will recollect that, in the case of the two patients who died with mental symptoms, glycosuria was found, though the quantity of sugar was certainly too small to warrant the suggestion that the mental disturbance was in any way connected with the condition known as acetonæmia. In all probability the sugar appeared in the urine as an evidence of a wider range of nervous disturbance than would appear to be common in exophthalmic goitre, a compass that may be supposed to include hepatic innervation.

With reference to the mental symptoms of Graves's disease, it is interesting to keep before our minds the observation of $\mathrm{Mr}$. Victor Horsley in the Brown Lectures on Pathology, delivered in 1885, on the thyroid gland, to the effect that imbecility is produced by removal of the gland. Respecting the functions of this body, he reminds ns of the opinions of Simon, Liebermeister, and others, who believed that it was a regulator of the cerebral circulation, and that it secreted something necessary to the perfect nutrition of the brain. That the thyroid plays an important part in relation to cerebral function there can be no doubt, and it is possible that the change it undergoes in Graves's disease may be in some measure responsible for the mental state.

In conclusion, permit me to direct your attention for a moment to the pathology of Graves's disease. The opinions advanced by authorities during the past half century have been numerous, but there are a fow that command special attention. Stokes ascribed the symptoms to a nenrosis of the heart and cervical vessels : Trousseau, Laycock, and Graefe to an affection of the sympathetic; Begbie to anæmia and nervo-disorder combined; Basedow to a dyscrasia allied to chlorosis ; Geigel to cord-lesion (cilio-spinal centre) ; Benedict to disesss of the medulla, etc. It seems to me that it is impossible to dissociate the sympathetic from the symptoms of the disease, for the heart-condition, nervousness, sweating, blushing, bronzing, the occasional dependence of the symptoms upon emotional disturbance or fright, all tend to strengthen the connection. The question arises, does a definite organic lesion necessarily underlie the group of symptoms, or may they not arise as the result of a pure neurosis of the sympathetic (functional disorder)? It is true that some pathologists have discovered more or less marked changes in the cervical ganglia, amongst whom I may mention Virchow, Peter, Recklinghausen, Traube, and Geigel. But, on the other hand, in many cases careful investigation has revealed nothing abnormal ; witngss the observations of Fournier, Ranvier, Ross, Rabejac, Wilks, Bristowe, Savage, Silcock, and others, a list to which I must add my own, for though I have examined microscopically the ganglia of the two cases referred to, I have not been able to detect any structural changes ; indeed, a comparison institated between these ganglia and the cervical sympathetic of a man 
who was killed by an accident convinced me that the formor were - absolutely normal in microscopical appearance. I have also oramined the medulla and supra-renal capsulo of the case in which cerebral symptoms developed, but with negative result. The view to which I am disposed to lean is, that the majority of the cases of Graves's disease are examples of a functional neurosis of the sympatbetic and perhaps of the associated centres in the cord and medulla (especially the latter). In proof of the functional, in opposition to the organic, theory may be urged the fact of the occasional sudden origin of the disease, the complete recovery in some cases, the sex most frequently attacked, the rarity of the development of the symptoms during pregnancy, the frequent association with other fornis of functional nervedisorder (insanity, etc.), and so forth. I am disposed to think that a wesk but irritable and instable condition of the cells of the ganglia of the sympathetic, due to, or connected with, a similar condition of the cord and medulla vaso-motor centres (cardio-vascular), will account for the palpitation as well as for many othor phenomena of the disorder. The thyroidal enlargement is, I believe, a simple hypertrophy in which both the vessels and glandtalar substance of the organ take part; and I do not think it is straining facts to assume that the hypertrophy is due to this instable and irritable condition of the ganglionic cells, inasmuch as they most probably preside over its nutrition. I remember a case of Graves's disease, in which the thyroid enlarged rapidly in one direction, sending off a bud-like offshoot, about the size of a large filbert, during an attack of tonsilitis. This projection, which was firm and entirely devoid of pulsation, was evidently composed of gland substance and not a simple vascular dilatation; it was interesting to note that during the attack, which only lasted a few days, the eyes stood out much more prominently than before, and receded as the temporary disturbance subsided. The proptosis is more difficult to explain, but I believe it depends chiefly upon these conditions-all of which are responsible for the phenomeronnamely, increase of $f_{\alpha t}$ in the orbit, postocular capillary dilatation, and degeneration and relaxation of the recti muscles.

\section{AN ADDRESS}

\section{STUDY OF HUMAN ANATOMY.}

Delivered at the Meeting held for the Formation of an Anatomical Socicty, May 6ith, 1S8\%.

BY PROFESSOR HUMPHRY, F.R.S.

Gentlexwy, - I fully appreciate the honour you have done me in voting me to the chair on this occasion. The reason for your doing so may be found in the fact that my commencement of the study of anatomy dates from more than half a century ago, during great part of which time I have been a teacher of anatomy ; and it is therefore pretty certain that $I$ am the senior anatomical student as well as the senior anatomical teacher here present; and though I have now to a great extent relinquished the study and teaching of anatomy, yet it may be supposed that I still cast lingering looks behind, upon that field in which I for so many years worked happily and earnestly, and $I$ hope not altogether unprofitably.

I appreciate the honour, however, more especially because I feel that this is an important occasion, an epoch it may perhaps be regarded, in the history of anatomy, and an occasion of much importance to the study of medicine generally. We are met together for the purpose of elevating the study of human anatomy, and placing, or endeavouring to place, the science of human anatomy on a level with, and in that proper relation to, the other branches of natural science, which I think it has not for some time held, and which relative decadence is greatly to be attributed to the fact that it has not advanced pari passu with them. Since the time of Hunter and Cruikshank and Astley-Cooper and the Bells, human anatomy has lacked its proper interest, and has not held its own with the other quickly progressing branches of natural science. Hence it has come to be regarded as a merely practical subject, and its study to be merely a process of piling fact upon fact without due regard to the purport of the facts and the suggestions to which they should give rise. Far be it from me to disparage the value of anatomy as a practical subject, seeing that in this way it confers the greatest benefits upon humanity, and has, and ever must have, the first and chief claim to our regard. Nor would I disparage the educational benefit resulting from the acquisition of a clesr and accurate knowledge of the structure of the body and the mental training derived thereby, which is of so much value to those who are entering upon the pursuit of medicine. But I feel that the study of anatomy should not be regarded from this point alone, but that a wider and higher view should be taken of it. The human body is undoubtedly the highest and most perfect of created works, the last and most perfect outcome of Nature's laboratory, the central one around which all the rest of the animal world is grouped, to which all point, and which all are calculated to elucidate. It is pro. vided with a surpassing mechanism, great results being produced by slight modifications from the forms of other animals, and the result. ants being such acuteness of perception, and such variety, nicety, and precision of movement, as to give man the mastery over all others, and enable him to bend all Nature to his purpose. Moreover, its proportions, the outlines of its form, and the power of expression of its several parts, in both sexes and at all periods of life, are such, and present 80 much beauty and variety, that it has formed subjects for the highest efforts of the greatest artists of all times, from Pheidias and Raphael to Leighton and Millais. Moreover, in it the physical is worked up into that complex and mysterious elaboration and pro. cess which enables it to become the organ or agent of the mental and intellectual-the seat of the soul, the abode of Deity. The problems and conceptions-physical, artistic, and psychical-arisirit out of it, of and associated with this material frame of ours, infinitely surpass, in number and interest, those of all other existing forms.

It may be regarded, therefore, as one of tho marvels connected with it, that the study of it should come to be regarded as dull, uuinteresting, and profitable only for its direct practical relations with meelicine and surgery. Surely it noeds only the proper impulses, such as we trust will in part be furnished by the proposed socioty, to obtain for it a due appreciation and position among the higher anl educa. tional sciences. It was this feeling which urged me to contend strongly, and, I am glad to say, successfully, for a place for hunan anatomy among the natural sciences at Cambridge; and I am convinced that it would be a benefit, vibrating along the whole line of medical education, if at the early stage of that education, the student were accustomed to reflect upon what he sees and reads of in his ana. tomical course, and to associate thoughts respecting the mechanical and other relations of the structures which he dissects. One of the greatest, perhaps the greatest, defects in medical education, I might say in all education more or less, but in medical education especially, is the heaping apon and oppressing the student's mind with a load of facts which he neither digests nor appropriates, and which he therefore does not retain. His mind is like a sack crammed with grain, which there is little power to fertilise or utilise. Far better would it be to lessen the load, and to substitute the habit and the ability to reflect, and really digest and appropriate the remainder, to give some opportunity for mental elasticity and for that enjoyment of study which results from a real knowledge and appreciation of what is learned. As a general rule, wo remember only, at any rate we remember best, that information the bearings of which we have well understood, which has consequently most interested and impressed us, and which we have most enjoyed. To make anatomy better remembered and a better mental training, it must be made more interesting and more attractive and more thought-inspiring; and this is to be done by giving to it its proper scope as a medium of information, and by imparting to its details, which are now too cold and dry and sterile, the warmth and life and thought-budding energy which should belong to them. I have spoken chiefly of human anatomy, because to it these remarks especially apply, and because the human body is the subject of the most serious and arduous study, and the manner in which it is prosecuted is the most important and the most relevant to our purpose. Not that the scope of the proposed society is to be limited to it, but that our greatest opportunities for good will be in relation to it. Anatomy, the anatony more particulaily of the human body, is a very ancient and dignified science, indoed a royal science. It was studied, ages and ages ago, by the people on the banks of the Nile, from whom we have derived so much; and, we were told the other day at Cambridge by my learned successor in the Chair of Anatomy, that the earliest writing upon anatomy of which we have any cognisance was by an Egsptian king who had passed away long before the Exodus took place. It is for us to make it a royal science, in a higher sense, and to give to the human body ite proper royalty of position in the animal world, not merely by having regard to the paramount practical importance of its study, but by considering it also in relation to its mechanism or physical physiology, in its relation to embryology, and in its relation to the anatomy of other animals, and also in its relation to the special structural features which may be associated with the 